\title{
Composição químico-bromatológica da forragem durante o período de ocupação em pastagens de capim-elefante (Pennisetum purpureum, Schum) e capim-mombaça (Panicum maximum, Jacq) sob manejo rotacionado
}

\author{
[Forage composition during the occupation period in elephant grass (Pennisetum purpureum, Schum) \\ and mombaça grass (Panicum maximum, Jacq) pastures under rotational system] \\ R.C. Clipes ${ }^{1}$, J.F.C. Silva ${ }^{2,4}$, E. Detmann ${ }^{3,4}$, H.M. Vásquez $z^{2,4}$ \\ ${ }^{1}$ Aluna de pós-graduação - UENF \\ Av. Alberto Lamego, 2000 \\ 28013 - Campos dos Goytacazes, RJ \\ ${ }^{2}$ Universidade Estadual Norte Fluminense - Campos dos Goytacazes, RJ \\ ${ }^{3}$ Universidade Federal de Viçosa - Viçosa, MG \\ ${ }^{4}$ Bolsista do CNPq
}

\begin{abstract}
RESUMO
Os valores nutritivos do capim-elefante e do mombaça foram avaliados por intermédio de amostras de extrusa esofágica, determinando-se a composição químico-bromatológica, o fracionamento dos compostos nitrogenados e carboidratos, e a digestibilidade in vitro da matéria seca. Foram utilizados 15 e 13 piquetes de capim-elefante e capim-mombaça, períodos de descanso de 42 e 36 dias, respectivamente, e período de ocupação de três dias. Em cada pastagem, eram mantidas quatro novilhas mestiças. As coletas de extrusa foram realizadas, seqüencialmente em cada piquete ocupado, de forma que se obtivessem amostras do terceiro, segundo e primeiro dias de ocupação. A comparação entre as médias das amostras de extrusa dos primeiros, segundos e terceiros dias de ocupação foi realizada por contrastes ortogonais e equações de regressão. No capim-mombaça foi observado comportamento quadrático $(\mathrm{P}<0,05)$ no teor de proteína bruta. Os teores de carboidratos totais, fibra em detergente neutro, fibra em detergente ácido, celulose e fração potencialmente degradável dos carboidratos $\left(\mathrm{B}_{2}\right)$ aumentaram linearmente $1,95,2,74,2,57,2,42$ e 2,3 pontos percentuais por dia sob pastejo, respectivamente $(\mathrm{P}<0,05)$. Houve redução na qualidade do capim-mombaça com o avançar do período de ocupação, principalmente, quanto ao acréscimo dos constituintes fibrosos. No capim-elefante não foram observadas alterações nas variáveis estudadas $(\mathrm{P}>0,05)$.
\end{abstract}

Palavras-chave: fracionamento protéico, fracionamento de carboidratos, extrusa esofágica

\begin{abstract}
The chemical composition, the fractions of nitrogenous and carbohydrates compounds and the in vitro dry matter digestibility, were evaluated in elephant and mombaça grasses pastures under rotational system. Fifteen paddocks of elephant grass and thirteen of mombaça grass were used with three days of occupation period and 42 and 36 days of resting periods, respectively. Extrusa samplings were done in order to get samples relating to third, second and first days of the occupation period. In each pasture were kept four crossbreds heifers. The comparison between the average composition of esophageal extrusa samples of to the first, second and third days of the occupation periods was done by the orthogonal contrast, with further adjustment by regression equations. For mombaça grass it was
\end{abstract}

Recebido em 1 de setembro de 2005

Aceito em 19 de maio de 2006

E-mail: clipes@uenf.br

Apoio: $\mathrm{CNPq}$ - CAPES 
observed quadratic behavior $(P<0.05)$ for crude protein content. In function of the occupation period carbohydrates, neutral detergent fiber, acid detergent fiber, cellulose and potentially degradable fraction of carbohydrates $\left(B_{2}\right)$, contents increased linearly by 1.95, 2.74, 2.57, 2.42 and 2.3 percent respectively by day of occupation $(P<0.05)$. The mombaça grass quality decreased with the occupation period, mainly due to increases in the fibrous constituents. Were no differences in the chemical composition of elephant grass were observed the occupation period $(P>0.05)$.

Keywords: protein faction, carbohydrate fraction, esophageal extrusa

\section{INTRODUÇ̃̃O}

As pastagens constituem a base da alimentação dos ruminantes na maioria dos sistemas de produção das regiões tropicais, e representam a forma mais prática e econômica de sustentação da bovinocultura no Brasil. Estima-se que $75 \%$ da superfície utilizada pela agricultura sejam ocupadas por pastagens, que correspondem a $20 \%$ da área total do País (Faria et al., 1996). Existe, entretanto, a necessidade de se obterem ganhos em produtividade, especialmente por minimização dos efeitos da sazonalidade quantitativa e qualitativa das forrageiras tropicais (Paulino, 1999).

De acordo com Euclides et al. (1989), qualquer sistema de pastejo envolve a manipulação de dois fatores importantes: a freqüência determinada pelos dias de pastejo e dias de descanso, e a intensidade de pastejo determinada pela pressão de pastejo.

Trabalhos revisados (Corsi, 1986; Maraschin, 1994) parecem concordar que espécies forrageiras de porte alto, eretas e com ritmo de crescimento acelerado, como as forrageiras das espécies Panicum maximum (capim-mombaça, capim-tanzânia, capim-colonião), Pennisetum purpureum (capim-elefante), são mais adaptadas ao sistema de pastejo rotacionado. Ao estudarem a curva de crescimento do capim-elefante, Andrade e Gomide (1971) verificaram que o vigor máximo da rebrota ocorreu com o corte aos 28 dias de idade, tendo ainda o seu valor nutritivo reduzido acentuadamente a partir desta idade. Pupo (1980) recomendou para o capimelefante cv. Napier, período de ocupação dos piquetes de 3 a 7 dias com 35 a 45 dias de descanso.

O período de ocupação dos animais sob pastejo influencia a produção animal, sendo que, quanto mais curto, melhor será o desempenho, já que assim evita maior flutuação no valor nutritivo da forragem entre o início e o fim do pastejo. De acordo com Gomide (1993), o período de ocupação dos animais sob pastejo rotacionado deve ser o mais curto possível, para aumentar a eficiência de uso da forragem e para prevenir uma segunda desfolhação do perfilho durante o período de ocupação, o que comprometeria sua recuperação por esgotar as reservas orgânicas basais.

Para Corsi (1993), o controle do estádio vegetativo (período de descanso) da forrageira, na época do pastejo, é o parâmetro que mais influi na sua qualidade nutricional, e varia conforme a espécie forrageira, na obtenção de melhor equilíbrio entre produção e qualidade da forragem.

Van Soest (1994) relatou que, para produção animal favorável utilizando-se pastejo rotacionado, deve-se levar em consideração a produção total e a qualidade das forrageiras pastejadas, pois, o material de alta qualidade é ingerido primeiro, produzindo perfil cíclico em função da transferência dos animais entre piquetes. Neste enfoque, quando os animais ocupam um piquete durante vários dias, o valor nutritivo da forragem consumida, maior no primeiro dia de pastejo, reduz-se com o avanço do período de ocupação.

Cóser et al. (1999), ao trabalharem com capimelefante por períodos de ocupação de um, três e cinco dias durante três anos, não verificaram diferenças significativas na produção de leite dos animais conforme o período de ocupação utilizado. Foram observadas, no entanto, variações nas produções diárias de leite, que decresceram com o passar dos dias de ocupação.

Dessa forma, o conhecimento da variação do valor nutritivo da forragem ao longo do período vegetativo é requisito para a correção de deficiências nutricionais, de forma a maximizar a 
utilização dos nutrientes disponíveis. Por isso, este trabalho foi proposto para determinar a composição químico-bromatológica, o fracionamento dos compostos nitrogenados e carboidratos, e a digestibilidade in vitro da matéria seca das amostras de extrusa obtidas no período de ocupação, em pastagens de capimelefante (Pennisetum purpureum, Schum cv. Napier) e capim-mombaça (Panicum maximum, Jacq cv. Mombaça) sob manejo rotacionado.

\section{MATERIAL E MÉTODOS}

O trabalho foi conduzido em pastagens rotacionadas constituídas por 15 piquetes de capim-elefante (Pennisetum purpureum, Schum. cv. Napier) e 13 piquetes de capim-mombaça (Panicum maximum, Jacq. cv. Mombaça), cujos piquetes apresentavam área de $600 \mathrm{~m}^{2}$, sendo manejados com período de ocupação de três dias e períodos de descanso de 42 e 36 dias para os capins elefante e mombaça, respectivamente.

Foram mantidas em cada pastagem, em regime exclusivo de pastejo, quatro novilhas mestiças Holandês-zebu, com peso e idade médios, ao início do experimento de $225 \mathrm{~kg}$ e 13 meses, as quais eram recolhidas ao centro de manejo às 17 horas, onde passavam o período noturno, retornando às pastagens no dia seguinte pela manhã.

Os piquetes receberam calagem (calcário dolomítico) conforme os resultados de análises de solo da área experimental para elevar a saturação de base para o nível de $60 \%$, realizando-se gradagem para incorporação do corretivo ao solo. Para a adubação foi utilizado superfosfato simples, para elevar o teor de fósforo para $20 \mathrm{mg} / \mathrm{dm}^{3}$, e adubação de cobertura com $150 \mathrm{~kg} /$ ha de $\mathrm{N}$, na forma de sulfato de amônio, além da aplicação de cloreto de potássio, suficiente para elevar o teor de potássio para $130 \mathrm{mg} / \mathrm{dm}^{3}$.

As amostragens das forrageiras foram realizadas por intermédio de extrusas esofágicas, entre os meses de junho e setembro de 2002, totalizandose dois ciclos de pastejo completos para ambas gramíneas.

As coletas foram realizadas seqüencialmente em cada piquete ocupado, alternando-se o momento de amostragem, visando à distribuição uniforme das coletas, de forma que, a cada grupo de três piquetes pastejados se obtivessem amostras relativas ao terceiro, segundo e primeiro dias de ocupação (Tab. 1), respectivamente, realizadas por dois novilhos 1/2 sangue Holandês-zebu, fistulados no esôfago, utilizando-se um animal por forrageira, casualizados anteriormente a cada coleta, submetidos a jejum por aproximadamente 12 horas, buscando-se evitar a contaminação das amostras com conteúdo ruminal por regurgitação no momento da coleta (Holecheck, 1982).

Os animais fistulados eram conduzidos até a área experimental às 7 horas da manhã, sendo retiradas as cânulas e colocadas as bolsas coletoras, confeccionadas em lona impermeável e com fundo telado. $\mathrm{O}$ período de pastejo foi de aproximadamente 40 minutos, procedendo-se depois à limpeza das fistulas e recolocação das cânulas, sendo os animais conduzidos de volta ao piquete anexo.

As amostras coletadas em cada animal foram imediatamente colocadas em sacos plásticos identificados e armazenadas em congelador a $15^{\circ} \mathrm{C}$. Posteriormente, as amostras foram submetidas à secagem em estufa de ventilação forçada (a $60^{\circ} \mathrm{C}$ - 72 horas) sendo processadas em moinho provido de peneira com porosidade de $1 \mathrm{~mm}$. Foram determinados os teores de matéria seca (MS), proteína bruta (PB), cinzas e extrato etéreo (EE) segundo técnicas descritas por Silva (1990), fibra em detergente neutro corrigida para cinzas e proteínas (FDNcp) e fibra em detergente ácido corrigida para cinzas e proteínas (FDAcp), celulose e lignina conforme padronizações de Van Soest et al. (1991).

As frações dos compostos nitrogenados, as quais consistem em compostos nitrogenados nãoprotéicos, com degradação ruminal instantânea (fração $\mathrm{A}$ ), peptídeos e oligopeptídeos, de rápida degradação (fração $\mathrm{B}_{1}$ ), proteínas citoplasmáticas de mediana degradação (fração $\mathrm{B}_{2}$ ), proteína insolúvel em detergente neutro potencialmente degradável (fração $\mathrm{B}_{3}$ ) e proteína insolúvel em detergente ácido não-degradável no trato gastrintestinal (TGI) (fração C) foram estimadas de acordo com as padronizações postuladas por Licitra et al. (1996) e Malafaia et al. (1997). A expressão de todas as frações nitrogenadas em equivalentes protéicos foi realizada pela multiplicação do respectivo teor em nitrogênio pelo fator 6,25 . 
Tabela 1. Cronograma de coletas de extrusa e simulação manual para cada ciclo de pastejo (ciclos de 45 dias para o capim-elefante* e 39 dias para o capim-mombaça)

\begin{tabular}{|c|c|c|c|}
\hline $\begin{array}{l}\text { Dia de } \\
\text { pastejo }\end{array}$ & Piquete & Dia de ocupação & Coletas \\
\hline 1 & 1 & 1 & - \\
\hline 2 & 1 & 2 & - \\
\hline 3 & 1 & 3 & $\mathrm{X}$ \\
\hline 4 & 2 & 1 & - \\
\hline 5 & 2 & 2 & $\mathrm{X}$ \\
\hline 6 & 2 & 3 & - \\
\hline 7 & 3 & 1 & $X$ \\
\hline 8 & 3 & 2 & - \\
\hline 9 & 3 & 3 & - \\
\hline 10 & 4 & 1 & - \\
\hline 11 & 4 & 2 & - \\
\hline 12 & 4 & 3 & $\mathrm{X}$ \\
\hline 13 & 5 & 1 & - \\
\hline 14 & 5 & 2 & $\mathrm{X}$ \\
\hline 15 & 5 & 3 & - \\
\hline 16 & 6 & 1 & $\mathrm{X}$ \\
\hline 17 & 6 & 2 & - \\
\hline 18 & 6 & 3 & - \\
\hline 19 & 7 & 1 & - \\
\hline 20 & 7 & 2 & - \\
\hline 21 & 7 & 3 & $\mathrm{X}$ \\
\hline 22 & 8 & 1 & - \\
\hline 23 & 8 & 2 & $\mathrm{X}$ \\
\hline 24 & 8 & 3 & - \\
\hline 25 & 9 & 1 & $X$ \\
\hline 26 & 9 & 2 & - \\
\hline 27 & 9 & 3 & - \\
\hline 28 & 10 & 1 & - \\
\hline 29 & 10 & 2 & - \\
\hline 30 & 10 & 3 & $X$ \\
\hline 31 & 11 & 1 & - \\
\hline 32 & 11 & 2 & $X$ \\
\hline 33 & 11 & 3 & - \\
\hline 34 & 12 & 1 & $X$ \\
\hline 35 & 12 & 2 & - \\
\hline 36 & 12 & 3 & - \\
\hline 37 & 13 & 1 & - \\
\hline 38 & 13 & 2 & - \\
\hline 39 & 13 & 3 & $X$ \\
\hline $40 *$ & 14 & 1 & - \\
\hline $41 *$ & 14 & 2 & X \\
\hline $42 *$ & 14 & 3 & - \\
\hline $43 *$ & 15 & 1 & $X$ \\
\hline $44 *$ & 15 & 2 & - \\
\hline $45 *$ & 15 & 3 & - \\
\hline
\end{tabular}

Os carboidratos totais (CT) compreendidos nas frações representadas pelos açúcares solúveis, os quais são prontamente fermentados no rúmen (fração A), fração constituída de amido e pectina, com taxas intermediárias de degradação (fração $\mathrm{B}_{1}$ ), fração lenta e potencialmente digerível da parede celular (fração $\mathrm{B}_{2}$ ) e porção indigerível ao longo do TGI (fração C) foram obtidas segundo Sniffen et al. (1992).Os carboidratos nãofibrosos (CNF) foram calculados de acordo com Weiss (1999).
A digestibilidade in vitro da matéria seca (DIVMS) nas amostras de extrusa foi estimada utilizando-se líquido ruminal de novilho mestiço, mantido em pastagem, segundo protocolos de Tilley e Terry (1963).

As disponibilidades de MS para ambas gramíneas foram estimadas conforme Scolforo (2003) e encontram-se na Tab. 2.

Tabela 2. Médias e desvios padrão da média para a disponibilidade de forragem $(\mathrm{kg} / \mathrm{MS} / \mathrm{ha}) \mathrm{em}$ cada ciclo de pastejo, para o capim-elefante e capim-mombaça, durante o período experimental

\begin{tabular}{lcc}
\hline Gramínea & Ciclo I & Ciclo II \\
\hline Capim-elefante & $1087 \pm 100$ & $1434 \pm 116$ \\
Capim-mombaça & $1895 \pm 183$ & $2456 \pm 192$ \\
\hline
\end{tabular}

A comparação entre as médias dos primeiros, segundos e terceiros dias de ocupação, foi realizada por intermédio de contrastes ortogonais para os efeitos de ordem linear e quadrática (Steel et al., 1997), com posterior ajustamento de equações de regressão linear. Para todos os procedimentos estatísticos adotou-se $\alpha=0,05$.

\section{RESULTADOS E DISCUSSÃO}

Os teores de MS, cinzas, EE, PB e CT das amostras de capim-elefante não foram alterados $(\mathrm{P}>0,05)$ com o decorrer dos dias sob pastejo (Tab. 3).

Os teores PB e EE das amostras das extrusas do capim-mombaça apresentaram comportamento quadrático $(\mathrm{P}<0,05)$. Para os teores de $\mathrm{CT}$, entretanto, verificou-se aumento linear $(\mathrm{P}<0,05) \mathrm{em}$ função dos dias sob pastejo. Quanto aos teores de MS e cinzas, não foram observadas diferenças $(\mathrm{P}>0,05)$ entre dias sob pastejo no capim-mombaça.

O ponto crítico estimado para os teores de PB obtidos na extrusa do capim-mombaça ocorreu em 2,8 dias de pastejo, equivalendo ao teor mínimo de $10,6 \%$. Contudo, todos os valores de proteína observados encontram-se acima do nível crítico de $7 \%$, abaixo do qual ocorre redução na digestibilidade e consumo em função da limitação do desenvolvimento da população microbiana do rúmen-retículo, alterando a fermentação ruminal (Van Soest, 1994). 
O ponto máximo estimado para o teor de EE na extrusa do capim-mombaça ocorreu em 1,8 dias, estimando-se teor de 1,9\%. Para os teores de CT, foi verificado incremento diário de 1,95 pontos percentuais.

Não foram observadas diferenças significativas $(\mathrm{P}>0,05)$ entre dias sob pastejo quanto aos teores de FDN, FDA, celulose e lignina nas amostras obtidas pela via extrusa esofágica para a pastagem de capim-elefante, possivelmente, em conseqüência da quantidade de folhas novas e pequenas observadas principalmente no terceiro dia de pastejo, sendo estas coletadas pelos animais fistulados no esôfago, o que pode ter influenciado na resposta observada.

Para a pastagem de capim-mombaça verificaramse incrementos lineares $(\mathrm{P}<0,05)$ sobre os teores de FDN, FDA e celulose, ao passo que não se observou diferença $(\mathrm{P}>0,05)$ quanto ao teor de lignina em função dos dias sob pastejo. O conhecimento desses valores é de fundamental importância, pois valores de FDN acima de 55$60 \%$ na matéria seca relacionam-se negativamente com o consumo de pasto (Van Soest, 1965).

Tabela 3. Médias (\%), coeficientes de variação (CV), níveis descritivos de probabilidade para contrastes $\left(\mathrm{P}^{\mathrm{a}}\right)$ para as concentrações de matéria seca $(\mathrm{MS})$, cinzas, extrato etéreo (EE), proteína bruta (PB), carboidrato total (CT), fibra em detergente neutro (FDN), fibra em detergente ácido (FDA), celulose, lignina e digestibilidade in vitro da matéria seca (DIVMS) em função do número de dias sob pastejo

\begin{tabular}{|c|c|c|c|c|c|c|}
\hline \multirow[b]{2}{*}{ Variáveis } & \multicolumn{3}{|c|}{ Dias em pastejo } & \multirow[b]{2}{*}{ CV (\%) } & \multicolumn{2}{|c|}{ Nível de probabilidade $\mathrm{P}^{\mathrm{a}}$} \\
\hline & 1 & 2 & 3 & & $\mathrm{~L}$ & $\bar{Q}$ \\
\hline \multicolumn{7}{|c|}{ Capim-elefante } \\
\hline MS & 13,52 & 13,23 & 12,97 & 3,2 & 0,0987 & 0,9654 \\
\hline Cinzas & 11,84 & 12,14 & 11,72 & 9,1 & 0,8807 & 0,6055 \\
\hline $\mathrm{EE}$ & 2,03 & 1,49 & 1,53 & 39,0 & 0,3093 & 0,4922 \\
\hline PB & 12,13 & 10,98 & 12,19 & 14,2 & 0,9577 & 0,2827 \\
\hline CT & 74,01 & 75,40 & 74,57 & 1,9 & 0,6018 & 0,2503 \\
\hline FDN & 63,38 & 66,07 & 65,28 & 4,9 & 0,4255 & 0,4009 \\
\hline FDA & 37,31 & 39,68 & 39,70 & 4,3 & 0,0797 & 0,2885 \\
\hline Celulose & 31,65 & 33,15 & 33,19 & 4,3 & 0,1559 & 0,4177 \\
\hline Lignina & 3,60 & 4,53 & 4,91 & 22,9 & 0,1006 & 0,6666 \\
\hline DIVMS & 65,61 & 64,53 & 64,34 & 3,9 & 0,4971 & 0,7793 \\
\hline \multicolumn{7}{|c|}{ Capim-mombaça } \\
\hline MS & 14,75 & 14,74 & 13,97 & 4,2 & 0,1099 & 0,3385 \\
\hline Cinzas & 13,74 & 13,97 & 14,33 & 7,2 & 0,4401 & 0,9191 \\
\hline $\mathrm{EE}^{\mathrm{b}}$ & 1,51 & 1,89 & 1,17 & 23,1 & 0,2026 & 0,0345 \\
\hline $\mathrm{PB}^{\mathrm{c}}$ & 14,75 & 11,41 & 10,61 & 2,7 & $<0,0001$ & 0,0002 \\
\hline$C T^{d}$ & 70,00 & 72,74 & 73,90 & 1,3 & 0,0004 & 0,2175 \\
\hline $\mathrm{FDN}^{\mathrm{e}}$ & 61,36 & 64,63 & 66,85 & 1,7 & 0,0001 & 0,4656 \\
\hline FDA $^{f}$ & 37,01 & 39,52 & 42,14 & 1,8 & $<0,0001$ & 0,9025 \\
\hline Celulose $\mathrm{g}^{\mathrm{g}}$ & 28,95 & 31,88 & 33,80 & 4,1 & 0,0007 & 0,5399 \\
\hline Lignina & 4,45 & 3,94 & 4,82 & 18,23 & 0,5276 & 0,1967 \\
\hline DIVMS & 57,77 & 55,95 & 58,19 & 9,40 & 0,9155 & 0,5547 \\
\hline
\end{tabular}

${ }^{\mathrm{a}} \mathrm{L}$ e Q - efeitos linear e quadrático para o número de dias sob pastejo, respectivamente. ${ }^{\mathrm{b}} \hat{Y}=2,0175-0,5475 \mathrm{X}+0,4470 \mathrm{X}^{2}$ $\left(\mathrm{R}^{2}=0,4470\right) .{ }^{\mathrm{c}} \hat{Y}=-7,1500+1,2700 \mathrm{X}+20,6275 \mathrm{X}^{2}\left(\mathrm{R}^{2}=0,9778\right) .{ }^{\mathrm{d}} \hat{Y}=68,3100+1,9513 \mathrm{X}\left(\mathrm{r}^{2}=0,8064\right) .{ }^{\mathrm{e}} \hat{Y}=9,5117-0,7888 \mathrm{X}$ $\left(\mathrm{r}^{2}=0,4782\right) .{ }^{\mathrm{f}} \hat{Y}=58,7917+2,7425 \mathrm{X}\left(\mathrm{r}^{2}=0,8585\right) .{ }^{\mathrm{g}} \hat{Y}=34,4225+2,5663 \mathrm{X}(\mathrm{r} 2=0,9267) .{ }^{\mathrm{h}} \hat{Y}=26,6950+2,4225 \mathrm{X}\left(\mathrm{r}^{2}=0,9662\right)$.

Foram observados incrementos de 2,74, 2,57 e 2,42 pontos percentuais por dia de pastejo $(\mathrm{P}<0,05)$ para FDN, FDA e celulose, respectivamente, nas amostras obtidas pela extrusa esofágica para o capim-mombaça, em decorrência da preferência dos animais por folhas, o que pode ter influenciado na maior quantidade de colmos após o primeiro dia sob pastejo, ocasionando aumento nos constituintes da parede celular. 
Blaser et al. (1986), ao trabalharem com três dias de ocupação, relataram que a produção de leite aumentou do primeiro para o segundo dia, e observaram decréscimo deste para o terceiro dia sob pastejo, ao passo que, com cinco dias de ocupação, verificaram aumento na produção de leite do primeiro para o terceiro dia, decrescendo novamente a produção no quinto dia de pastejo. Esses mesmos autores relataram que as oscilações citadas anteriormente estão associadas à disponibilidade de forragem e seletividade no pastejo, onde, no primeiro dia, a forragem consumida apresenta valor nutritivo mais elevado.

Os incrementos observados entre os dias sob pastejo para os teores de CT, FDN, FDA e celulose para o capim-mombaça indicam aumento dos constituintes da parede celular, o que acarreta queda na qualidade da forragem após o primeiro dia sob pastejo. Com a ocupação dos animais no primeiro dia, conseqüentemente, em virtude da melhor qualidade e maior uniformidade da pastagem espera-se maior produção de leite no segundo dia.
A DIVMS das amostras de extrusa não apresentou diferença $(\mathrm{P}>0,05)$ em função dos dias sob pastejo para as gramíneas avaliadas. Os valores médios entre os dias sob pastejo foram de 64,83 e $57,30 \%$ para o capim-elefante e capim-mombaça, respectivamente. Esses valores estão acima do considerado satisfatório, segundo Hillesheim (1992), que sugeriu DIVMS mínima de 55\% para plantas forrageiras tropicais, não influenciando, dessa forma, no consumo voluntário de forragens.

Não foram observadas diferenças $(\mathrm{P}>0,05)$ quanto aos teores de $\mathrm{CNF}$, fração $\mathrm{B}_{2} \mathrm{e}$ fração $\mathrm{C}$ nas amostras de extrusa esofágica da pastagem de capim-elefante, em função do número de dias sob pastejo (Tab. 4). No capim-mombaça foi verificado decréscimo linear na concentração de CNF da ordem de 0,8 pontos percentuais ao dia e na fração $\mathrm{B}_{2}$, aumento linear de 2,3 pontos percentuais ao dia, provavelmente em conseqüência do aumento das frações fibrosas, após o primeiro dia em pastejo, enquanto que a fração $\mathrm{C}$ dos carboidratos totais não alterou $(\mathrm{P}>0,05)$ em função do número de dias sob pastejo.

Tabela 4. Médias (\%), coeficientes de variação (CV), níveis descritivos de probabilidade para contrastes $\left(\mathrm{P}^{\mathrm{a}}\right)$ para as concentrações dos carboidratos não fibrosos, frações $\mathrm{B}_{2}$ e $\mathrm{C}$ dos carboidratos totais em função do número de dias sob pastejo

\begin{tabular}{|c|c|c|c|c|c|c|}
\hline \multirow{2}{*}{ Variáveis } & \multicolumn{3}{|c|}{ Dias em pastejo } & \multirow[b]{2}{*}{$\mathrm{CV}(\%)$} & \multicolumn{2}{|c|}{ Nível de probabilidade $\mathrm{P}^{\mathrm{a}}$} \\
\hline & 1 & 2 & 3 & & $\mathrm{~L}$ & $\mathrm{Q}$ \\
\hline \multicolumn{7}{|c|}{ Capim-elefante } \\
\hline $\mathrm{CNF}$ & 10,63 & 9,33 & 9,29 & 21,0 & 0,3822 & 0,6292 \\
\hline Fração $B_{2}$ & 54,74 & 55,18 & 53,51 & 7,2 & 0,6697 & 0,6744 \\
\hline $\begin{array}{l}\text { Fração C } \\
\text { Capim-1 }\end{array}$ & 8,64 & 10,90 & 11,77 & 22,7 & 0,0981 & 0,6458 \\
\hline $\mathrm{CNF}^{\mathrm{b}}$ & 8,64 & 8,11 & 7,06 & 10,4 & 0,0268 & 0,6155 \\
\hline Fração $\mathrm{B}_{2}{ }^{\mathrm{c}}$ & 50,68 & 55,16 & 55,27 & 4,0 & 0,0167 & 0,1355 \\
\hline Fração C & 10,68 & 9,46 & 11,58 & 18,2 & 0,5281 & 0,1942 \\
\hline
\end{tabular}

${ }^{\mathrm{a}} \mathrm{L}$ e $\mathrm{Q}$ - efeitos linear e quadrático para o número de dias sob pastejo, respectivamente. ${ }^{\mathrm{b}} \hat{Y}=9,5117-0,7888, \mathrm{X}\left(\mathrm{R}^{2}=0,4782\right)$. ${ }^{c} \hat{Y}=49,12+2,2913 \mathrm{X}\left(\mathrm{R}^{2}=0,5317\right)$.

A natureza e a concentração dos CF são os principais determinantes da qualidade dos alimentos volumosos. Verificou-se incremento de 2,3 pontos percentuais $(\mathrm{P}<0,05)$ por dia no período de ocupação na fração $\mathrm{B}_{2}$ dos carboidratos totais (Tab. 4) das amostras de extrusas da pastagem de capim-mombaça, em razão da elevada proporção de colmos, visto que as folhas são ingeridas em maior quantidade nos primeiros dias de pastejo e acarreta, no terceiro dia, maior conteúdo de parede celular e finalmente pelos acréscimos lineares encontrados nos teores de FDN, FDA e celulose (Tab. 3).
Os teores médios dos carboidratos não-fibrosos (CNF), frações $\mathrm{B}_{2}$ e $\mathrm{C}$ dos carboidratos totais (\% CT) para o capim-elefante foram de 14,4. 74 e $11,7 \%$ para os CNF, frações $\mathrm{B}_{2}$ e $\mathrm{C}$, respectivamente, nas amostras obtidas por extrusa para o primeiro dia de ocupação (Fig. 1), enquanto que, no terceiro dia, os teores médios foram de $12,7,71,6$ e $15,7 \%$, respectivamente. O capimmombaça apresentou teores de $12,3,2,4$ e $15,3 \%$ para as respectivas frações.Os teores encontrados, entretanto, no terceiro dia de ocupação, foram de $9,5,4,8$ e $15,7 \%$, respectivamente. 


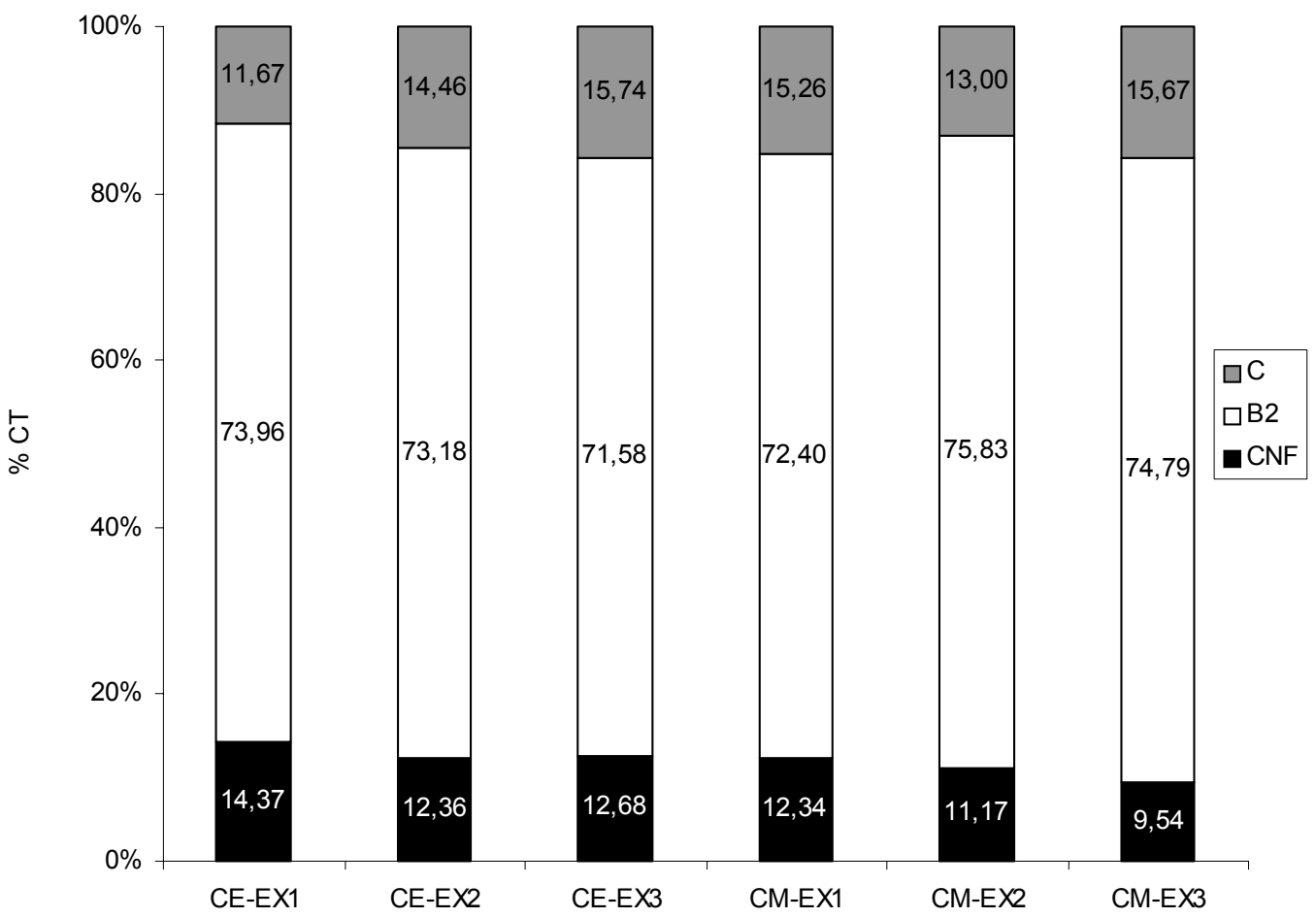

Figura 1. Teores médios dos carboidratos não-fibrosos (CNF) e frações $B_{2}$ e $C$ como porcentagem dos carboidratos totais $(\mathrm{CT})$ de acordo com as gramíneas capim-elefante (CE) e capim-mombaça (CM) segundo a metodologia de amostragem extrusa esofágica (EX) nos diferentes dias sob pastejo.

Não foram observadas diferenças $(\mathrm{P}>0,05)$ para os teores das diferentes frações dos compostos nitrogenados $(\% \mathrm{MS})$ nas amostras das extrusas do capim-elefante em função dos dias sob pastejo (Tab. 5). Para as amostras do capimmombaça, a fração A apresentou comportamento quadrático com valor mínimo estimado $(1,1 \%)$, aos 2,6 dias de pastejo $(P<0,05)$, enquanto que, as frações $\mathrm{B}_{2}$ e $\mathrm{B}_{3}$ apresentaram decréscimos lineares de 0,65 e 0,84 pontos percentuais por dia.

Não foram observados $(P>0,05)$ efeitos linear e quadrático para as frações $\mathrm{B}_{1} \mathrm{e} \mathrm{C}$ dos compostos nitrogenados das amostras de extrusas da pastagem de capim-mombaça em função do número de dias sob pastejo.
Os teores médios das frações $A, B_{1}, B_{2}, B_{3}$ e $C$ dos compostos nitrogenados $(\% \mathrm{~PB})$ obtidos para a extrusa do capim-elefante foram de 16,7, 6,0, $44,4,27,8$ e $5,1 \%$, respectivamente, no primeiro dia de ocupação, enquanto que, foram observados valores de $15,1,7,6,7,9,33,0$ e $6,4 \%$ no terceiro dia de ocupação (Fig. 2).

O capim-mombaça apresentou teores de 17,5, $4,4,32,8,40,3$ e $5,0 \%$ no primeiro dia de ocupação para as frações $\mathrm{A}, \mathrm{B}_{1}, \mathrm{~B}_{2}, \mathrm{~B}_{3}$ e $\mathrm{C}$ dos compostos nitrogenados (\%PB), respectivamente, e teores de 10,5, 8,2, 33,3, 40,2 e $7,9 \%$ para o terceiro dia de ocupação. 
Tabela 5. Médias (\%), coeficientes de variação (CV), níveis descritivos de probabilidade para contrastes $\left(\mathrm{P}^{\mathrm{a}}\right)$ para as concentrações das frações dos compostos nitrogenados em função do número de dias sob pastejo

\begin{tabular}{|c|c|c|c|c|c|c|}
\hline \multirow[b]{2}{*}{ Variáveis } & \multicolumn{3}{|c|}{ Dias em pastejo } & \multirow[b]{2}{*}{ CV $(\%)$} & \multicolumn{2}{|c|}{$\begin{array}{l}\text { Nível de probabilidade } \\
\mathrm{P}^{\mathrm{a}}\end{array}$} \\
\hline & 1 & 2 & 3 & & $\mathrm{~L}$ & Q \\
\hline \multicolumn{7}{|c|}{ Capim-elefante } \\
\hline Fração A & 2,02 & 1,40 & 1,85 & 42,7 & 0,7465 & 0,2738 \\
\hline Fração B1 & 0,73 & 0,89 & 0,92 & 47,9 & 0,5150 & 0,7925 \\
\hline Fração B2 & 5,38 & 4,42 & 4,62 & 16,3 & 0,2069 & 0,2588 \\
\hline Fração B3 & 3,37 & 3,55 & 4,03 & 18,8 & 0,2154 & 0,7278 \\
\hline Fração C & 0,62 & 0,72 & 0,78 & 20,0 & 0,1531 & 0,8127 \\
\hline \multicolumn{7}{|l|}{ Capim-mombaça } \\
\hline Fração $A^{b}$ & 2,58 & 1,26 & 1,11 & 11,4 & $<0,0001$ & 0,0009 \\
\hline Fração B1 & 0,65 & 0,89 & 0,87 & 37,3 & 0,3271 & 0,5046 \\
\hline Fração $B 2^{c}$ & 4,83 & 3,64 & 3,53 & 10,5 & 0,0024 & 0,0699 \\
\hline 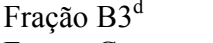 & 5,94 & 4,91 & 4,26 & 9,2 & 0,0009 & 0,5154 \\
\hline Fração C & 0,74 & 0,72 & 0,84 & 20,4 & 0,3930 & 0,4566 \\
\hline
\end{tabular}

${ }^{\mathrm{a}} \mathrm{L}$ e Q - efeitos linear e quadrático para o número de dias sob pastejo, respectivamente. ${ }^{\mathrm{b}} \hat{Y}=5,0800-3,0875 \mathrm{X}+0,5875 \mathrm{X}^{2}$ $\left(\mathrm{R}^{2}=0,7667\right) .{ }^{\mathrm{c}} \hat{Y}=5,3050-0,6525 \mathrm{X}\left(\mathrm{R}^{2}=0,7054\right) .{ }^{\mathrm{d}} \hat{Y}=6,7141-0,8388 \mathrm{X}\left(\mathrm{r}^{2}=0,7651\right)$.

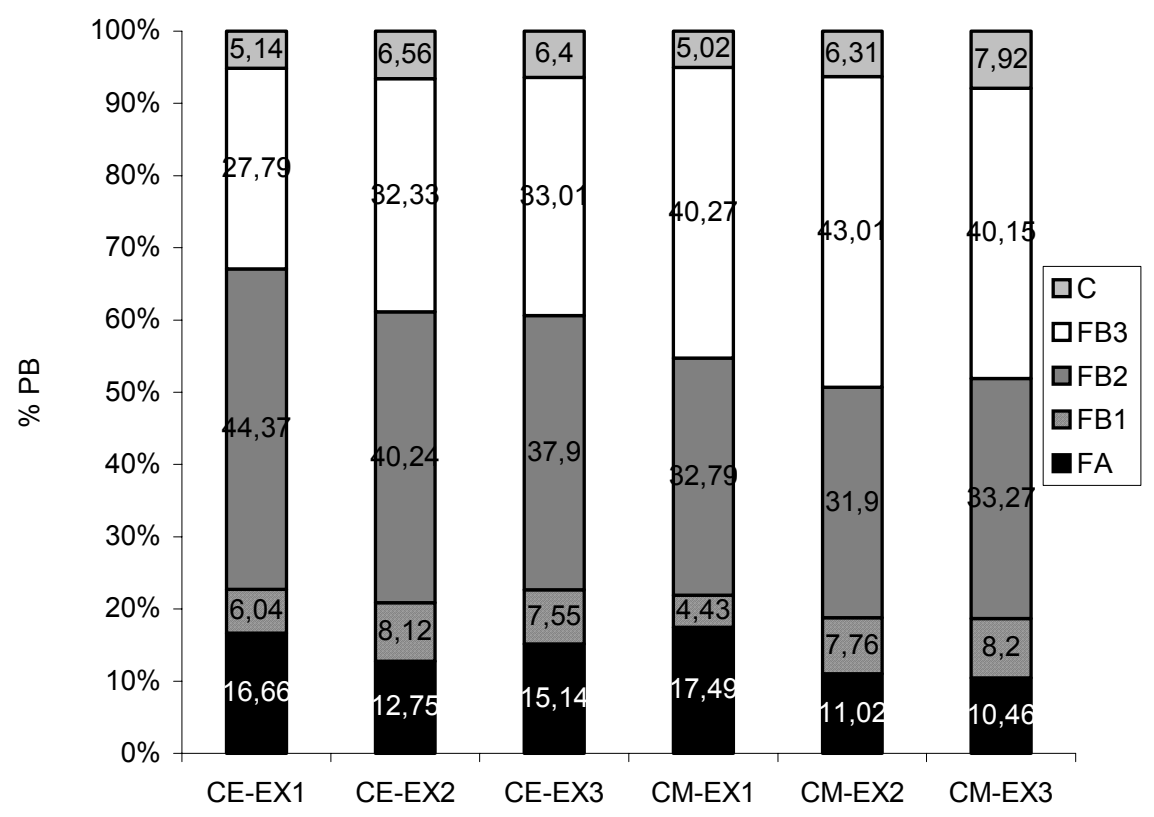

Figura 2. Teores médios das diferentes frações dos compostos nitrogenados, como porcentagem da proteína bruta $(\% \mathrm{~PB})$, de acordo com as gramíneas capim-elefante (CE) e capim-mombaça (CM) conforme a metodologia de amostragem extrusa esofágica (EX) nos diferentes dias sob pastejo.

\section{CONCLUSÕES}

Não há alterações nas características de avaliação da qualidade do capim-elefante com o avançar do período de ocupação estudado. Verifica-se redução na qualidade da pastagem de capim-mombaça com o passar do período de ocupação, principalmente no tocante ao acréscimo dos constituintes da parede celular após o início do período de pastejo. 


\section{REFERÊNCIAS BIBLIOGRÁFICAS}

ANDRADE, I.F.; GOMIDE, J.A. Curva de crescimento e valor nutritivo do capim-elefante (Pennisetum purpureum Schum.). R.. Ceres, v.100, p.431-447, 1971.

BLASER, R.E.; HAMMES JR.; R.C. FONTENOT, J.P. et al. Animal management systems. Virginia Agricultural Experimental Station, 1986. 90p.

CORSI, M. Parâmetros para intensificar o uso das pastagens. In: BOVINOCULTURA DE CORTE: FUNDAMENTOS DA EXPLORAÇÃO RACIONAL, 1993, Piracicaba. Anais... Piracicaba: FEALQ, 1993. p.209-230.

CORSI, M. Pastagens de alta produtividade. In: SIMPÓSIO SOBRE MANEJO DA PASTAGEM, 8.,1986, Piracicaba. Anais... Piracicaba: FEALQ, 1986. p.499-512.

CÓSER, A.C.; MARTINS, C.E.; FONSECA, D.M. et al. Efeito de diferentes períodos de ocupação da pastagem de capim-elefante sobre a produção de leite. Pesq. Agropec. Bras., v.34, n.5, p.861-866, 1999.

EUCLIDES, V.P.B.; ZIMMER, A. H.; VIEIRA, J.M. et al. Equilíbrio na utilização de forragem sob pastejo. In: SIMPÓSIO SOBRE ECOSSISTEMAS DE PASTAGENS, 1989, Jaboticabal. Anais... Jaboticabal: FUNEP, 1989. p.271-313.

FARIA, V.P.; PEDREIRA, C.G.S.; SANTOS, F.A.P et al. Evolução do uso de pastagens para bovinos. In: SIMPÓSIO SOBRE MANEJO DAS PASTAGENS, 13., 1996, Piracicaba. Anais... Piracicaba: FEALQ, 1996. p. 1-14.

GOMIDE, J.A. Produção de leite em regime de pasto. R. Bras. Zootec., v.22, n.4, p.591-613, 1993.

HILLESHEIM, A. Manejo do capim-elefante: Corte. IN: SIMPÓSIO SOBRE MANEJO DE PASTAGEM, 10., 1992, Piracicaba. Anais... Piracicaba: FEALQ, 1992. p.117-141

HOLECHECK, J. L.; VAVRA, M.; PIEPER, R. D. Methods for determining the nutritive quality of range ruminant diets: A Review. J. Anim. Sci., v.54, p.363375, 1982.

LICITRA, G.; HERNANDEZ, T.M.; VAN SOEST, P.J. Standardization of procedures for nitrogen fractionation of ruminant feeds. Anim. Feed Sci. Technol., v.57, n.4, p.347-358, 1996.

MALAFAIA, P.A.M.; VALADARES FILHO, S.C.; VIEIRA, R.A.M. et al. Determinação e cinética ruminal das frações protéicas de alguns alimentos para ruminantes. R. Bras. Zootec., v.26, n.6, p.1243-1251, 1997.

MARASCHIN, G.E. Avaliação de forrageiras e rendimento de pastagens com o animal em pastejo. In: CECATO, U. et al. (ed.). In: SIMPÓSIO INTERNACIONAL DE FORRAGICULTURA, 1994, Maringá. Anais... Maringá: Sociedade Brasileira de Zootecnia, 1994. p.65-98.

PAULINO, M.F. Misturas Múltiplas na nutrição de bovinos de corte a pasto. In: SIMPÓSIO GOIANO SOBRE PRODUÇÃO DE BOVINOS DE CORTE, 1 ., 1999. Goiânia. Anais... Goiânia, 1999. p.95-104.

PUPO, N.I. Manual de pastagens e forrageiras: formação, conservação, utilização. Campinas: Instituto Campineiro de Ensino Agrícola, 1980. 343p.

SCOLFORO, L. Avaliação de sistemas de produção e viabilidade econômica, na recria de novilhas em pastagens rotacionadas, com uso de banco de proteína. 2003. 60f. Dissertação (Mestrado) Universidade Estadual do Norte Fluminense, Campos dos Goytacazes.

SILVA, D.J. Análises de Alimentos (métodos químicos e biológicos). 2.ed. Viçosa: Imprensa Universitária, $1990.165 \mathrm{p}$.

SNIFFEN. C.J.; O' CONNOR, J.D.; VAN SOEST, P.J. et al. A net carbohydrate and protein system for evaluating cattle diets: II. Carbohydrate and protein availability. J. Anim. Sci., v.70, p.3562-3577, 1992.

STEEL, R.G.; TORRIE, J.H.; DICKEY, D.A. Principles and procedures of statistics. A biometrical approach. New York: McGraw-Hill lo, 1997. 666p.

TILLEY, J.M.A.; TERRY, R.A. A two-stage technique for the in vitro digestion of forage crops. $J$. Br. Grassl. Sci., v.18, p.104-111, 1963.

VAN SOEST, P. J. Nutritional ecology of the ruminant. Cornell University. 2 ed. New York: Cornell University, 1994. 476p.

VAN SOEST, P. J. Symposium on factors influencing the voluntary intake of herbage by ruminants: Voluntary intake relation to chemical composition and digestibility. J. Anim. Sci., v.24, n.3, p.834-844, 1965.

VAN SOEST, P.J.; ROBERTSON, J.B.; LEWIS, B.A. et al. Methods for dietary fiber, neutral detergent fiber, and nonstarch polysaccharides in relation to animal nutrition. J. Dairy Sci., v.74, n.10, p.3583-3597, 1991.

WEISS, W.P. Energy prediction equations for ruminant feeds. In: CORNELL NUTRITION CONFERENCE FOR FEED MANUFACTURERS, 61, Proceedings... Ithaca: Cornell University, 1999. p.176-185. 